\title{
Cyanobacteria-shrimp colonies in the Mariana Islands
}

\author{
Christopher A. Leber • Andres Joshua Reyes - Jason S. Biggs • William H. Gerwick (D)
}

Received: 31 July 2020 / Accepted: 3 February 2021 / Published online: 27 February 2021

(C) The Author(s) 2021

\begin{abstract}
Cyanobacteria have multifaceted ecological roles on coral reefs. Moorena bouillonii, a chemically rich filamentous cyanobacterium, has been characterized as a pathogenic organism with an unusual ability to overgrow gorgonian corals, but little has been done to study its general growth habits or its unique association with the snapping shrimp Alpheus frontalis. Quantitative benthic surveys, and field and photographic observations were utilized to develop a better understanding of the ecology of these species, while growth experiments and nutrient analysis were performed to examine how this
\end{abstract}

Handling editor: Télesphore Sime-Ngando.

Supplementary Information The online version of this article (https://doi.org/10.1007/s10452-021-09837-6) contains supplementary material, which is available to authorized users.

C. A. Leber · W. H. Gerwick ( $\square)$

Center for Marine Biotechnology and Biomedicine,

Scripps Institution of Oceanography, University of

California, San Diego, La Jolla, CA 92093, USA

e-mail:wgerwick@ucsd.edu

A. J. Reyes · J. S. Biggs ( ()

University of Guam Marine Laboratory, UOG Station,

Mangilao, GU 96923, USA

e-mail: biggs.js@gmail.com

W. H. Gerwick

Skaggs School of Pharmacy and Pharmaceutical Sciences, University of California, San Diego, La Jolla,

CA 92093, USA cyanobacterium may be benefiting from its shrimp symbiont. Colonies of M. bouillonii and A. frontalis displayed considerable habitat specificity in terms of occupied substrate. Although found to vary in abundance and density across survey sites and transects, $M$. bouillonii was consistently found to be thriving with $A$. frontalis within interstitial spaces on the reef. Removal of A. frontalis from cyanobacterial colonies in a laboratory experiment altered $M$. bouillonii pigmentation, whereas cyanobacteria-shrimp colonies in the field exhibited elevated nutrient levels compared to the surrounding seawater.

Keywords Moorena bouillonii - Alpheus frontalis . Symbiosis · Cyanobacteria $\cdot$ Snapping shrimp · Coral reefs

\section{Introduction}

Cyanobacteria, also known as blue-green algae, represent a wide array of organisms that operate in a diversity of roles in marine ecosystems. In addition to producing oxygen via photosynthesis, some cyanobacteria can also fix nitrogen; these capabilities make cyanobacteria important primary producers in many marine systems, especially in oligotrophic open ocean environments (Carpenter, Subramaniam and Capone 2004). Conversely, cyanobacteria, often empowered 
by anthropogenic perturbations, can disrupt aquatic ecosystems by forming sustained and deleterious blooms (CyanoHABs) that produce toxins and can cause localized hypoxia (Paerl and Paul 2012). In the context of coral reef ecosystems, a similar dichotomy can be identified. In addition to CyanoHABs occurring in and around coral reefs, cyanobacteria have been implicated in coral diseases, such as black band disease and grey-patch disease (Frias-Lopez et al. 2003; Sweet et al. 2019). Cyanobacteria also contribute positively to coral reef ecosystems, serving as habitat and sources of food (Cruz-Rivera and Paul 2002, 2006), and engaging in specialized symbioses, including with sponges (Schorn et al 2019) and shrimp (Banner and Banner 1982).

One intriguing interaction between a cyanobacterium and a tropical reef organism that was serendipitously observed through drug discovery efforts in the Tropical Western Pacific (Tan, Márquez and Gerwick 2002) is the association between the filamentous cyanobacterium Moorena bouillonii (Hoffmann and Demoulin) (Engene and Tronholm 2019) (Oscillatoriaceae) and a symbiotic snapping shrimp Alpheus frontalis $\mathrm{H}$. Milne Edwards 1837 (Alpheidae) (Fig. 1). A. frontalis was first described in 1837 (MilneEdwards 1837), and reports of its association with M. bouillonii date back to as early as 1880 (Richters 1880), when two shrimp were collected from Mauritius in woven tubes of cyanobacteria, which at the time were identified as Oscillatoria sp. A. frontalis weaves M. bouillonii filaments into labyrinthine shelters consisting of interconnected tunnels and chambers (see Supplementary Video S1). Alpheus frontalis (often collected with $M$. bouillonii) has been documented in various publications, catalogs of crustacean taxonomy, and collection records, suggesting that this partnership extends from the eastern African coast and the Red Sea, across the Indian Ocean, and throughout the Tropical Western Pacific, bounded by Australia, Southern Japan, and French Polynesia (Richters 1880; Fishelson 1966; Nomura et al. 1996; Poupin 1998; Simões, Apel and Jones 2001; Davie and Short 2001).

While much of the scholarly effort directed towards A. frontalis has focused on its taxonomic classification and distribution, research on $M$. bouillonii has largely centered on its rich secondary metabolite chemistry relevant to human health. In fact, the entire genus Moorena (previously Moorea, formerly a part of Lyngbya) has been identified as a prolific source of biologically active compounds (Leão et al. 2017; Tronholm and Engene 2019). Since its initial description in 1991 (Hoffmann and Demoulin 1991), more than 60 unique natural products have been discovered from M. bouillonii (according to the MarinLit database [https://pubs.rsc.org/marinlit/] and SciFinder [https:// scifinder.cas.org/]), including the apratoxins, a family of exquisitely potent cancer cell cytotoxins (Luesch et al. 2001). In terms of driving ecological interactions among reef organisms, metabolites isolated from the closely related $M$. producens (previously Lyngbya majuscula) have been shown to be strong herbivore feeding deterrents (Nagle and Paul 1999); this has led to speculation that $M$. bouillonii may be producing similar anti-predatory chemicals that could also benefit its cohabitants.

Despite the passage of over one hundred years since the discovery of the $M$. bouillonii-A. frontalis a

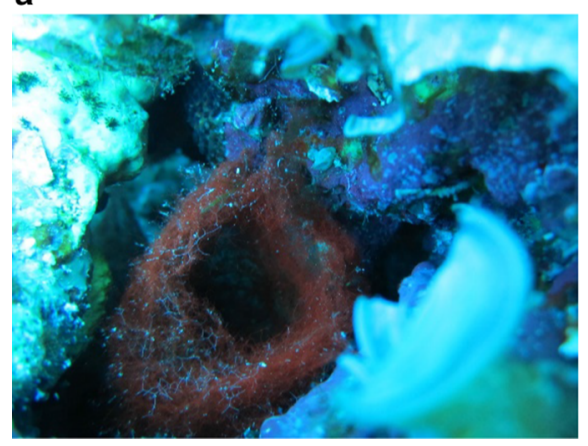

b

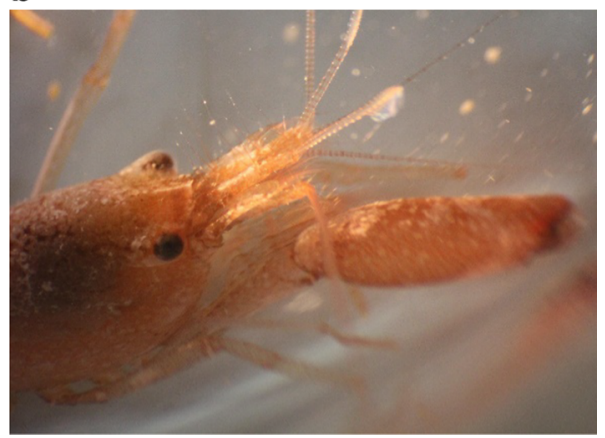

Fig. 1 Moorea bouillonii and Alpheus frontalis. a A woven tube of the filamentous cyanobacterium M. bouillonii and b its shrimp symbiont $A$. frontalis 
association, there have been strikingly few ecological investigations of either species. The weaving behavior of A. frontalis was first described in 1913 (Cowles 1913). This was built upon in a 1966 report that briefly described the habitat of $M$. bouillonii and A. frontalis colonies and detailed how pairs of shrimp interact with M. bouillonii in the laboratory to construct shelters (Fishelson 1966). Cruz-Rivera and Paul (2002, 2006) further described the commensal nature of this association in their studies of cyanobacteria as sources of food and shelter on coral reefs, highlighting the specificity of the M. bouillonii-A. frontalis pairing, articulating the protective behaviors observable in the shrimp, and noting the shrimp's use of the cyanobacteria for both food and shelter. Various other manuscripts also noted these interactions, but the nature of their association and the extensive structures created through the remarkable weaving skills of these shrimp remain to be elucidated.

Without detailed ecological studies, it is difficult to characterize $M$. bouillonii and A. frontalis as an emerging threat to coral reef health and resiliency. Experiments measuring effects of the cyanobacteria coming into contact with corals suggest that $M$. bouillonii natural products are toxic to corals and/or their symbionts and may serve as allelopathic agents that provide a competitive advantage against healthy corals (Titlyanov, Yakovleva and Titlyanov 2007). Additionally, localized blooms of $M$. bouillonii near Okinawa were reported as a major driver of mortality for the gorgonian Annella reticulata (Yamashiro, Isomura and Sakai 2014). Although somewhat in contrast to the historical knowledge of this speciespair's distribution and habits on coral reefs, these studies curiously suggest a complexity and context dependence for the ecological roles played by $M$. bouillonii and A. frontalis.

Herein, we describe efforts towards a more thorough and expansive understanding of $M$. bouillonii and its symbiotic association with $A$. frontalis in the context of coral reef systems found within the Mariana Islands. We achieve this by combining historical perspectives along with contemporary field studies and experiments. Moreover, we attempt to clarify the ecological relationships of this symbiotic pair among the stony corals with which they become associated, hypothesizing that the engulfing overgrowth of gorgonians by $M$. bouillonii as reported by Yamashiro et al. (2014) may not represent $M$. bouillonii ecology within all reef ecosystems. We address this hypothesis through in situ observations and photography, quantitative surveys of abundance and habitat, and culturing experiments designed to measure how $M$. bouillonii may benefit from its association with $A$. frontalis. With this foundation of knowledge, we hope to expand knowledge regarding the ecology of $M$. bouillonii and A. frontalis on coral reefs.

\section{Methods}

Surveys and Underwater Photography

Abundance surveys were conducted in the Mariana Islands (Fig. 2a) at Laulau Bay, Saipan, Commonwealth of the Northern Mariana Islands, USA

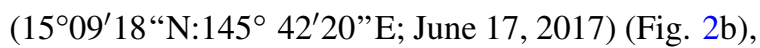
and Finger Reef, Apra Harbor, Guam, USA

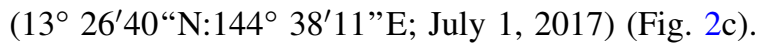
Each consisted of two 50-m transects, haphazardly placed in areas of high M. bouillonii abundance. All M. bouillonii colonies within $1 \mathrm{~m}$ of either side of the transect that displayed morphologies consistent with shrimp association (e.g., displayed the "cobweb," woven, tube-forming morphology indicative of recent weaving activity by shrimp.) were recorded $\left(100 \mathrm{~m}^{2}\right.$ per transect). Shrimp were not often visible during surveys but could reliably be detected by coming into gentle contact with surfaces of $M$. bouillonii that displayed shrimp-associated morphologies and waiting for the distinct, and often startling "snap" of a defending shrimp. Colonies were also photographed. M. bouillonii growing without shrimp, which has previously been reported on Guam (Matthew, Schupp, and Luesch 2008), was occasionally observed near transects at Finger Reef growing beneath overhanging reef structures. These cyanobacterial growths were not included in colony counts as the growth morphology is much more dispersed and without discrete, distinct colonies. Records were kept for each consecutive $20-\mathrm{m}^{2}$ area (10 linear meters) in order to capture the local variability and patchiness in colony distribution at these smaller scales. Surveys of each transect were conducted simultaneously by two different SCUBA divers experienced in recognizing $M$. bouillonii-A. frontalis colonies, after which the midpoints between the counts of both divers were calculated per $20-\mathrm{m}^{2}$ segment. The Laulau Bay abundance surveys were 

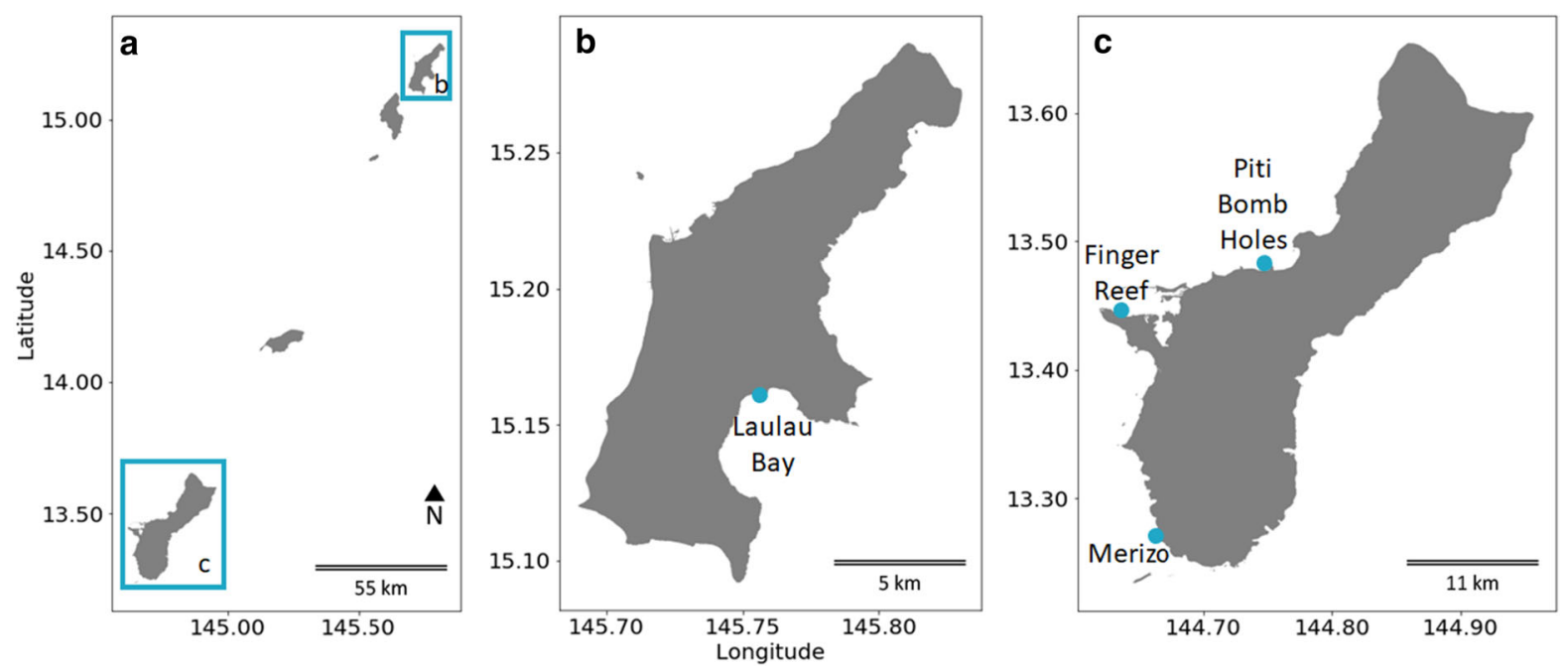

Fig. 2 Maps of a The Mariana Islands, b Saipan, and c Guam with marked survey sites. M. bouillonii-A. frontalis colony growth form and abundance was surveyed on the reefs in Laulau Bay, Saipan, and Finger Reef, Apra Harbor, Guam, while colony substrate preference was surveyed on Finger Reef, on the reef at

conducted along the 10- and 12-m depth contours, while the Finger Reef abundance surveys were conducted along the 7- and 12-m depth contours on the reef slope. Means and sample standard deviations for colonies $/ \mathrm{m}^{2}$ were calculated using each $10-\mathrm{m}$ segment along the 50-m transects as replicates and computed using Microsoft Excel. The purpose of the abundance surveys was to quantitatively characterize the concentration and distribution of $M$. bouillonii colonies across different reefs. They also allowed for the photographic documentation of the varied growth morphologies presented by colonies.

Substrate surveys were conducted at Finger Reef, Apra Harbor, Guam, USA (132 26'40“N:144³8'11”E; May 31, 2018), Piti Bomb Holes, Guam, USA (13 $28^{\prime} 15^{\prime \prime N}: 144^{\circ} 42^{\prime} 04^{\prime \prime} \mathrm{E}$; June 1, 2018), and a fringing reef shoreward of Cocos Lagoon in Merizo, Guam, USA (13 $16^{\prime} 12^{\prime \prime N}: 144^{\circ} 39^{\prime} 42^{\prime \prime} \mathrm{E}$; June 13, 2018) (Fig. 2c). Each consisted of two to three 50-m transects, haphazardly placed in areas of high $M$. bouillonii-A. frontalis colony abundance. One survey at Finger Reef was conducted on the reef flat, between 1 and $2 \mathrm{~m}$ depth, and the other was conducted on the reef slope around the 9-m depth contour. Surveys at Piti Bomb Holes were conducted between less than 1 and $2 \mathrm{~m}$ on the reef flat near its boundary
Piti Bomb Holes, Guam, and on a fringing reef in Merizo, Guam. Sites are marked on the maps with blue dots. The map was created using a NOAA-produced coastline shapefile (NOAA 2005)

with the reef slope. The surveys on the Merizo fringing reef were conducted between 1 and $3 \mathrm{~m}$ at the boundary between the reef flat and reef slope. All $M$. bouillonii colonies within $1 \mathrm{~m}$ of either side of the transect that displayed morphologies consistent with shrimp association were photographed, providing a record of the substrate occupied. Colonies were attributed substrate types based upon the structure they were contacting; in cases where colonies were contacting multiple substrates, substrate was assigned based on the majority of contacts. Videos were also recorded along each transect to document surrounding benthic habitat and provide additional context for determining substrate occupied by colonies with multiple contacts. Both photographs and videos were captured using a Canon PowerShot ${ }^{\circledR}$ ELPH 100 HS set for underwater macro-photography or video mode, respectively. Additional observational photographs were made via SCUBA from various locations on Guam, and via snorkeling in Laulau Bay, Saipan. The purpose of the substrate surveys was to ascertain the frequencies and site specificity of substrate occupation, thereby providing additional information about how M. bouillonii colonies grow on Marianas' reefs. 
Taxonomic identifications

Moorena bouillonii-A. frontalis colonies were identified in the field based on their distinctive woven-tube morphology and deep red color (Fig. 1a). Moreover, snapping shrimp such as $A$. frontalis defend against other organisms that physically disturb their cyanobacterial colony by rapidly closing their major chela, which results in a distinctive popping noise that announces their presence within the woven structure. In most cases, the visual or audible presence of $A$. frontalis provided further morphotaxonomic verification during our surveys. Care was also taken to examine cryptic locations within the reef structure, as the cyanobacteria-shrimp colonies are often nestled within crevices and around the bases of solid substrata. Small Sects. $\left(1-3 \mathrm{~cm}^{2}\right)$ of colonies were collected and examined via compound light microscopy to inspect the woven $M$. bouillonii tubes for other species of cyanobacterial filaments. In addition, partial $16 \mathrm{~S}$ rRNA gene sequences were obtained from both shrimp-associated and non-shrimp-associated $M$. bouillonii for final confirmation of field identifications (see Fig. S1 and Supplementary Methods).

\section{Culturing experiment}

Alpheus frontalis and M. bouillonii growing with (shrimp-associated cyanobacterium) and without $A$. frontalis (non-shrimp-associated cyanobacterium) were collected from Apra Harbor, Guam (with additional shrimp collected near Merizo, Guam) and used to assemble four different growth conditions in reusable plastic food storage containers: shrimpassociated cyanobacterium with a shrimp, shrimpassociated cyanobacterium without a shrimp, nonshrimp-associated cyanobacterium with a shrimp, and non-shrimp-associated cyanobacterium without a shrimp, each with five replicates. Weighted containers were covered with window screen, placed in a blocked arrangement, and submerged in a flow-through raw seawater table. Submersion allowed for water exchange and the deposition of materials for shrimp to scavenge in each container, while the mesh was intended to prevent shrimp escape. The water table was covered with $50 \%$ shade cloth to limit light stress. The experiment was conducted over 15 days (June 11, 2016, to June 26, 2016), with photographs taken each day to document changes in $M$. bouillonii pigmentation and wet weights of cyanobacterial biomass recorded on the first and last days. Excess water was removed from cyanobacterial biomass prior to wet weight measurements using a salad spinner. For each sample, the salad spinner was pumped 20 times at a rate of 1 pump per second, followed by a 10-s period of unconstrained spinning. Statistical analysis of changes in wet weight were conducted using the statsmodel package for Python 3 to build a two-way ANOVA model. Type of cyanobacteria (shrimp versus non-shrimp) and presence or absence of shrimp were set as independent variables for the two-way ANOVA, and an additional term was added to account for the blocked experimental design.

Nutrient analyses

Five paired water samples were collected from Finger Reef, Apra Harbor, Guam on July 3, 2017. Syringes $(50 \mathrm{~mL})$ with blunt-tip needles were used to collect water from inside the woven tubes and chambers of five individual shrimp-associated $M$. bouillonii colonies, and from approximately one meter above each colony in the water column. Samples were flash frozen in dry ice and kept frozen until they were submitted for nutrient analyses at the Oceanographic Data Facility, Scripps Institution of Oceanography, San Diego, California. Statistical significance was determined for each nutrient using Student's t-test (paired, twotailed), administered in Microsoft Excel.

\section{Results}

Abundance surveys

Field abundance surveys of M. bouillonii-A. frontalis colony growth in Laulau Bay, Saipan (Fig. 2b) and at Finger Reef in Apra Harbor, Guam (Fig. 2c), indicate that colony density varies greatly within and among reefs. The two transects on the reef in Laulau Bay revealed higher densities of $M$. bouillonii-A. frontalis colonies $\left(\right.$ mean $=4.73,3.01$ colonies per $\mathrm{m}^{2}$; standard deviation (sd) $=0.79,0.49 ; n=5)$ than the two transects on the reef slope of Finger Reef $\left(\right.$ mean $=0.47,1.33$ colonies per $\mathrm{m}^{2} ; \mathrm{sd}=0.61,1.50$; $n=5$ ) (see Fig. 3 and Supplementary Table S1). In consideration of colony density at a smaller scale, it is of note that the most densely populated transect 


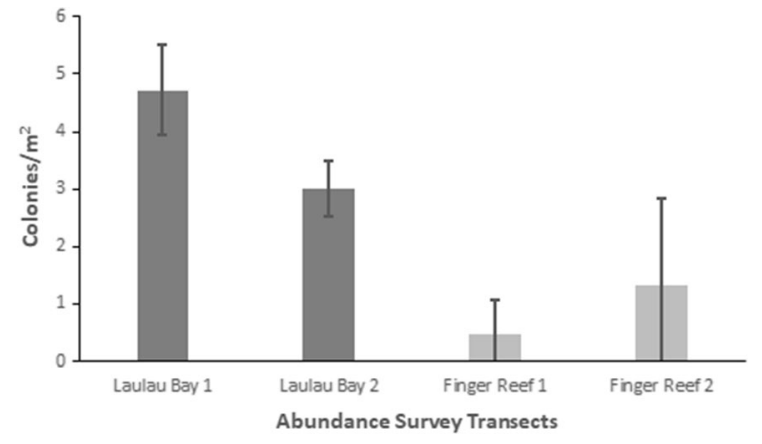

Fig. 3 M. bouillonii-A. frontalis colony density and abundance. $M$. bouillonii-A. frontalis colonies were found to be consistently abundant and densely occupying the reef in Laulau Bay, while colony density and abundance was more varied on Finger Reef. Note: For each transect, colonies along each linear $10 \mathrm{~m}\left(20 \mathrm{~m}^{2}\right)$ of the $50-\mathrm{m}$ transect were separately counted and recorded and make up the replicates represented by the standard deviation error bars

surveyed in Laulau Bay was composed of the top five most densely populated $10 \mathrm{~m}$ increments $(5.8,5.2,4.5$, 4.2, and 3.9 colonies per $\mathrm{m}^{2}$ ); however, the sixth most densely populated 10-m segment of reef was surveyed on Finger Reef, with 3.8 colonies per $\mathrm{m}^{2}$. Every $10-\mathrm{m}$ interval along the Saipan transects recorded densities greater than two M. bouillonii-A. frontalis colonies per square meter, and the most densely populated Saipan transect in particular represents an area of consistent high-density $M$. bouillonii-A. frontalis colony growth $\left(\right.$ mean $=4.73$ colonies per $\mathrm{m}^{2}$; $\mathrm{sd}=$ $0.79 ; n=5$ ). The two transects in Guam, however, ranged from 3.75 to 0.05 colonies per $\mathrm{m}^{2}$ and from 1.5 to 0.08 colonies per $\mathrm{m}^{2}$, with the former illustrating wide variation in colony density even within small spatial scales $(s d=1.50)$. Of particular note, while many colonies were observed to be in contact with stony coral, none of the colonies observed during the abundance surveys were found to display morphologies that would suggest coral overgrowth (e.g., cyanobacterial biomass engulfing the extended, external surfaces of corals)(see Supplementary Fig. S2).

\section{Substrate surveys}

Substrate surveys conducted around the island of Guam at Finger Reef in Apra Harbor, Piti Bomb Holes, and a fringing reef by Merizo (Fig. 2c) yielded detection of shrimp-associated $M$. bouillonii colonies growing mainly in coral-associated interstitial spaces.
Colonies were documented to predominantly grow in association with Porites rus and Porites cylindrica, with a much smaller number of colonies growing on bare reef substrate and only two colonies found growing with Porites cf. deformis (see Fig. 4 and Supplementary Table S2). Colonies were not found growing on any other substrate types during these surveys. Porites rus was the predominant colony substrate for both the reef flat and reef slope transects at Finger Reef, hosting $83 \%$ and $91 \%$ of documented colonies, respectively. P. cylindrica hosted most of the documented colonies at the Merizo reef, with $78 \%$ and 97\%, respectively. Transects at Piti Bomb Holes were less consistent, with $76 \%$ of the colonies along the first transect growing with P. rus, while $97 \%$ of colonies along transect two and $93 \%$ along transect three were growing with $P$. cylindrica. In agreement with the abundance surveys, while colonies were found to be growing among live coral substrate, none of the colonies observed during the substrate surveys displayed a morphology consistent with coral overgrowth, and macroscopically, none of the corals appeared to be injured by their associated cyanobacteria-shrimp colonies.

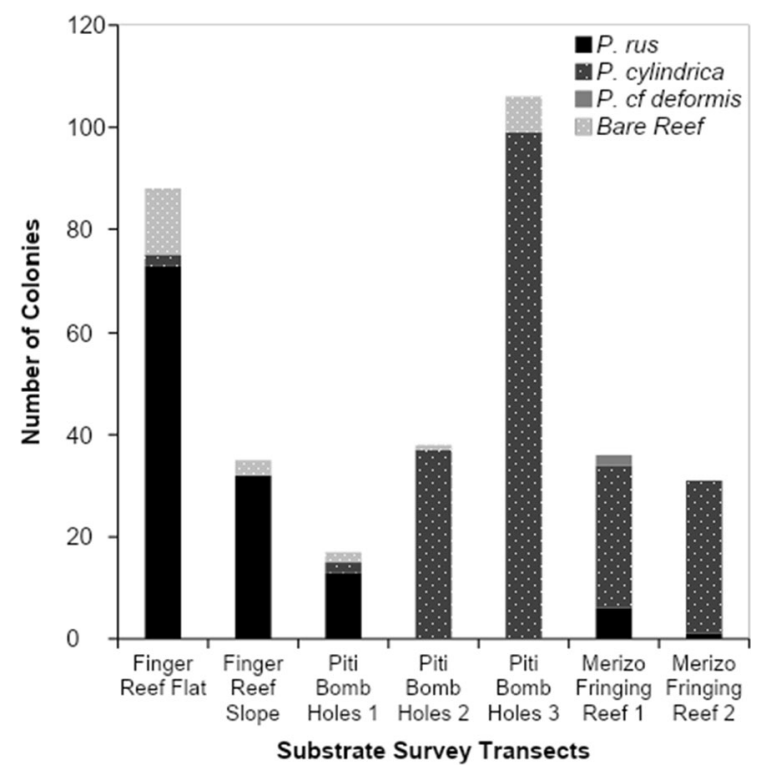

Fig. 4 M. bouillonii-A. frontalis colony substrate distribution. M. bouillonii-A. frontalis colonies were most often found occupying interstitial spaces among Porites rus and $P$. cylindrica corals and were not found to display growth morphologies indicative of coral overgrowth 
Culturing experiment

The photographic time series conducted during the culturing experiment revealed generally consistent patterns in pigmentation change for each of the four growth conditions (Fig. 5). Non-shrimp associated cyanobacteria began the experiment with a red-orange hue occasionally accented with yellow-green filaments, which quickly developed into a darker, deeper red hue when grown with shrimp, but remained relatively unchanged when grown without. Shrimp associated cyanobacteria appeared dark red and heavily pigmented at the onset of the experiment. In the absence of shrimp, shrimp associated cyanobacteria dramatically changed appearance, rapidly shifting from dark red filaments to a bright green, gelatinous mass. By day fifteen, the shrimp associated cyanobacteria grown without a shrimp appeared to begin to recover, with new filament growth becoming visible extending out of the green mass. Shrimp associated cyanobacteria grown with shrimp proved to be the least consistent growth condition in this study-two replicates retained dark red pigmentation, two replicates developed patches of green, and one replicate changed to a dark green coloration. This lack of consistency can be explained by the inadvertent removal of the three shrimp living in the three replicates that displayed greening - two died during the course of the experiment (blocks B and D), and one escaped (block A) (see Fig. S3, for complete photographic time course).

Out of the four growth conditions, non-shrimp associated cyanobacteria grown without a shrimp was the only condition that averaged net positive growth, as measured by change in wet weight (mean $=0.37 \mathrm{~g}$, $\mathrm{sd}=0.54 \mathrm{~g}, n=5$ ) (Fig. 6, Table S3). Mean change in wet weight was close to zero for shrimp associated cyanobacteria grown without a shrimp (mean = $-0.14 \mathrm{~g}, \mathrm{sd}=0.59 \mathrm{~g}, n=5$ ), while both types of cyanobacteria grown with a shrimp decreased in wet weight on average (shrimp associated: mean $=-0.92$ $\mathrm{g}$, sd $=0.78 \mathrm{~g}, n=5$; non-shrimp associated: mean $=$ $-0.61 \mathrm{~g}, \mathrm{sd}=0.54 \mathrm{~g}, n=5$ ). Two-way ANOVA accounting for the blocked experimental design was administered to test the statistical significance of the effects that cyanobacterial type and shrimp presence had on changes in wet weight. The blocked experimental design $(F=10.71, p$ value $<0.01)$, type of cyanobacteria $(\mathrm{F}=7.41, p$ value $<0.05)$, and presence of shrimp $(F=34.14$, $p$ value $<0.01)$ were all found to have statistically significant effects on cyanobacterial growth, as measured by changes in wet weight, while the interaction between cyanobacterial type and shrimp presence was not found to be significant $(F=0.43, p$ value $=0.53)($ Table S4). The significant effect of the blocked experimental design is attributable to the heterogeneity of flow environments in the water table in which the experiment took place; blocks differed in their proximity to inflow and outflow of seawater in the table.

\section{Comparative nutrient analyses}

From Finger Reef, Apra Harbor, Guam, five pairs of water samples were collected from inside M. bouillonii-A. frontalis colonies and approximately one meter above each colony. The pairs of samples were analyzed for their concentrations of silicate, $\mathrm{PO}_{4}{ }^{3-}$, $\mathrm{NO}_{3}{ }^{-}, \mathrm{NO}_{2}{ }^{-}$, and $\mathrm{NH}_{4}{ }^{+}$. For all five measured nutrients, statistically significant differences in

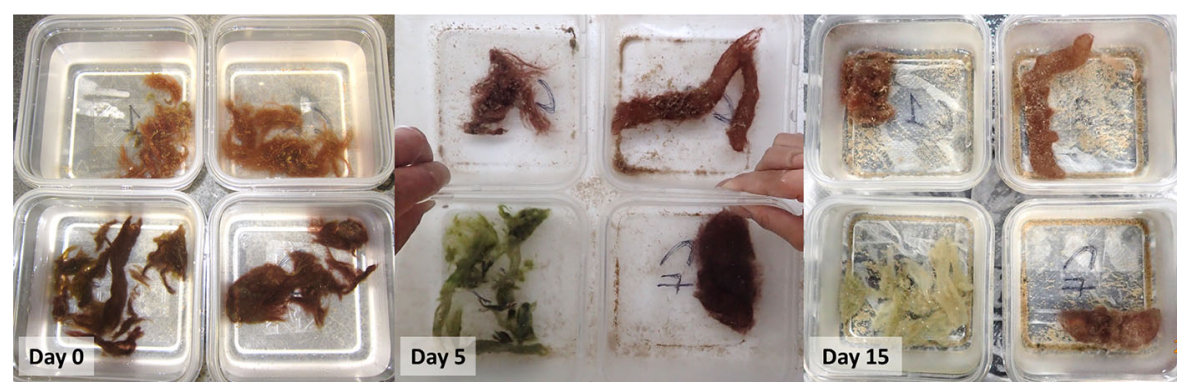

Fig. 5 Days 0, 5, and 15 of a representative block (block C) in the photographic time series of the $M$. bouillonii culturing experiment. Representative images from days 0,5 , and 15 of the photo time series of the $M$. bouillonii culturing experiment.
Clockwise from top left: non-shrimp associated cyanobacterium without a shrimp, non-shrimp associated cyanobacterium with a shrimp, shrimp associated cyanobacterium with a shrimp, and shrimp associated cyanobacterium without a shrimp 


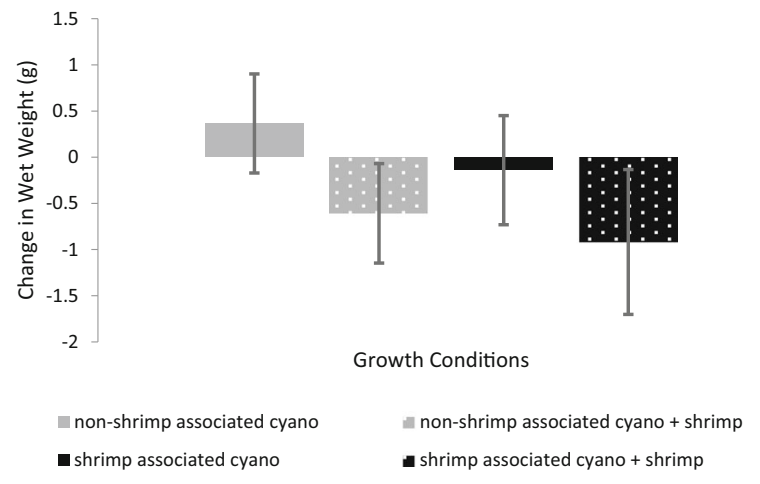

Fig. 6 Changes in wet weight from the M. bouillonii culturing experiment. Presence of shrimp corresponded to negative changes in wet weight, indicating a loss in cyanobacterial biomass resulting from shrimp feeding. Two-way ANOVA accounting for the blocked experimental design indicated statistically significant effects on changes in wet weight attributable to the type of cyanobacteria $(F=7.41$, $p$ value $<0.05)$, the presence of shrimp $(F=34.14$, $p$ value $<0.01)$, and the blocked experimental design $(F=10.71, p$ value $<0.01)$. The interaction between cyanobacterial type and shrimp presence was not found to be significant $(F=0.43, p$ value $=0.53)$

concentration between colonies and ambient seawater were detected (Table 1, Table S5). Colonies were shown to have significantly higher concentrations of $\mathrm{PO}_{4}{ }^{3-}, \mathrm{NO}_{3}{ }^{-}, \mathrm{NO}_{2}{ }^{-}$, and $\mathrm{NH}_{4}{ }^{+}$, while ambient seawater was measured to have higher concentrations of silicate.

\section{Discussion}

Study of M. bouillonii-A. frontalis colonies across the surveyed reefs in Laulau Bay and Apra Harbor allowed for the identification of three common habits of M. bouillonii growth (Fig. 7). The first growth form is cryptic and recessed, with colonies growing in crevices and extending deep into or under live or dead coral. The second is entrenched, where colonies extend from under horizontal shelves of coral. The third consists of semi-exposed tubes and chambers of M. bouillonii winding between and around upright coral structures, particularly the columnar growths of $P$. rus and the branches of $P$. cylindrica. It is common for large colonies to display multiple growth forms, which appear to be largely driven by the type of benthic structures available for the secure attachment of $M$. bouillonii, and so are highly plastic. On Finger Reef, $P$. rus is extremely prevalent and serves as the major substrate for $M$. bouillonii-A. frontalis colonies in this area. Both the entrenched growth form, found extending from under $P$. rus plates, as well as tubes winding around the bases of columnar P. rus, were common. In contrast, Laulau Bay is much more varied in its benthic structure, with apparent higher coral species diversity, areas of substantial algal and cyanobacterial growth, and regions of hard substrate devoid of live corals. The cryptic growth form of $M$. bouillonii was particularly common at this site; shrimp-constructed colonies were frequently located in crevices, holes, and other areas not occupied by corals or other algae. Of the close to one thousand colonies that were counted during the abundance surveys and over three hundred fifty colonies documented in the substrate surveys combined over these various reefs, although many colonies were observed in direct contact with corals, none were observed with growth morphologies suggesting overgrowth of these substrates encountered. This suggests that M. bouillonii-A. frontalis colonies most likely do not interact with stony corals in the same manner as previously

Table 1 Summary of paired water sample nutrient analysis data, revealing statistically significant differences in nutrient concentration between the water column and M. bouillonii colonies for all nutrients measured. $(n=5)$

\begin{tabular}{llllll}
\hline & $\mathrm{NO}_{3}{ }^{-} \mu \mathrm{mol} / \mathrm{L}$ & $\mathrm{PO}_{4}{ }^{3-} \mu \mathrm{mol} / \mathrm{L}$ & Silicate $\mu \mathrm{mol} / \mathrm{L}$ & $\mathrm{NO}_{2}{ }^{-} \mu \mathrm{mol}^{-L}$ & $\mathrm{NH}_{4}{ }^{+} \mu \mathrm{mol} / \mathrm{L}$ \\
\hline Water column mean & 0.402 & 0.038 & 2.3 & 0.004 & 0.444 \\
Water column sd & 0.165 & 0.013 & 0.158 & 0.009 & 0.088 \\
Colony mean & 1.032 & 0.148 & 2.1 & 0.05 & 0.678 \\
Colony sd $^{\text {a }}$ & 0.466 & 0.055 & 0.187 & 0.014 & 0.241 \\
value $^{\mathrm{a}}$ & 0.0200 & 0.0056 & 0.0217 & 0.0016 & 0.0404 \\
\hline
\end{tabular}

${ }^{a} p$ values from Student's $t$ test (paired, two tailed) 

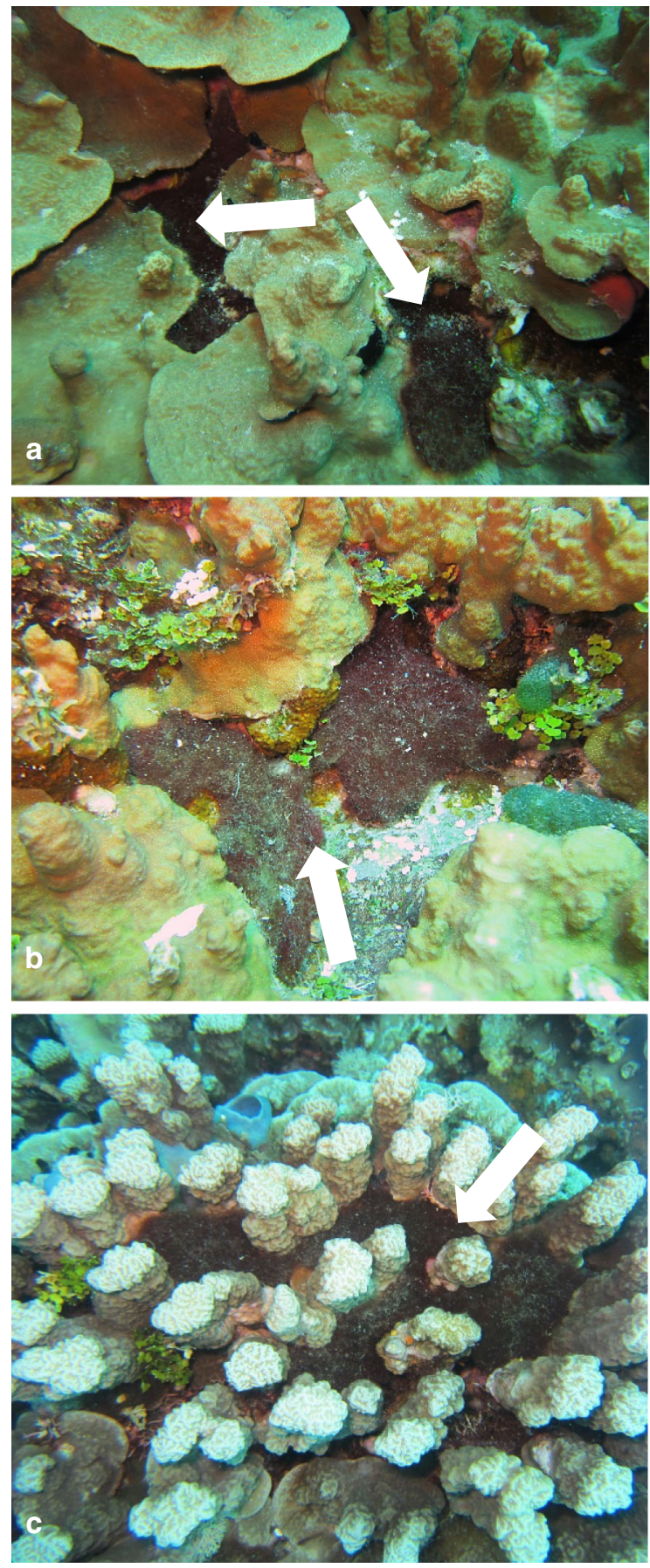

Fig. 7 Examples of $M$. bouillonii-A. frontalis colony growth habits observed in Saipan and Guam. Colonies of $M$. bouillonii and $A$. frontalis take different growth morphologies related to the substrate they are occupying. Colonies grow a Cryptic and recessed in holes and crevices, $\mathbf{b}$ Entrenched under shelves of hard substrate, and c Semi-exposed and winding around columnar structures. Colonies are denoted by white arrows reported for the octocoral A. reticulata near Okinawa (Yamashiro, Isomura and Sakai 2014). This was particularly notable in Laulau Bay, where there is substantial overgrowth on the reef by other species of cyanobacteria and macroalgae (Fig. 8).

The three $M$. bouillonii-A. frontalis colony growth forms observed in this study share the common characteristic of occupying interstitial spaces within and around their substrates, rather than growing over outer exposed surfaces. As the most colonized substrates in our study, the stony corals $P$. rus and $P$. cylindrica are morphologically endowed with a high degree of such interstitial features. $P$. rus grows in a plate form, under which $M$. bouillonii-A. frontalis colonies are commonly entrenched, as well as a columnar form, around the bases of which tubes of woven M. bouillonii typically wind. Similarly, the branches of $P$. cylindrica provide structures around which tubes of shrimp-associated $M$. bouillonii commonly encircle. The columns of $P$. cf. deformis, as well as eroded crevices and columns in old reef structures, provide additional, less frequently inhabited refugia for these cyanobacterial-shrimp colonies.

Two notable substrates that were not documented as being occupied by M. bouillonii-A. frontalis colonies were soft corals and macroalgae. Along with $P$. rus and P. cylindrica, soft coral species of the genus Sinularia have been documented to be prevalent at Piti Bomb Holes (Gochfeld 2010), and these soft corals

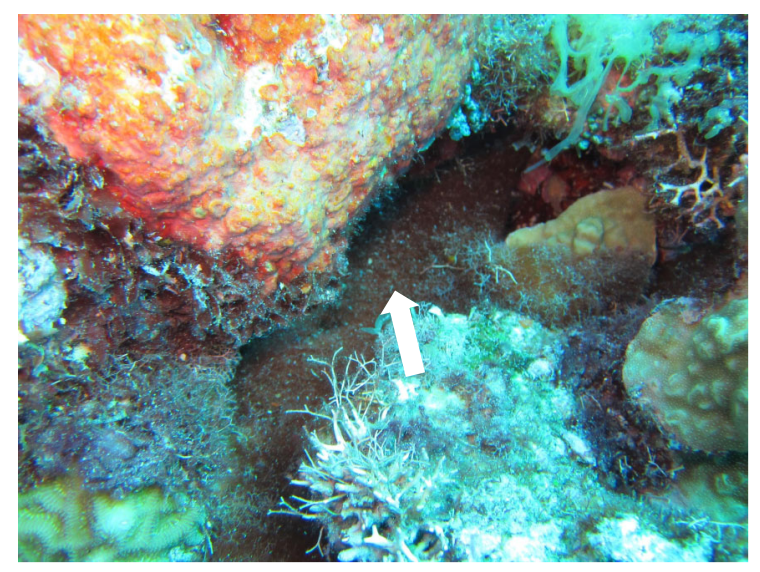

Fig. 8 M. bouillonii-A. frontalis colony growing in Laulau Bay reef crevice. Amidst other algae and cyanobacteria that are overgrowing parts of the reef in Laulau Bay, M. bouillonii-A. frontalis colonies can be found growing in an apparently benign fashion in interstitial and cryptic spaces. Colony is denoted by white arrow 
were noted along the transects at this site. Even though Sinularia species have branching structures providing substantial interstices, M. bouillonii-A. frontalis colonies were not found growing among them. In terms of macroalgae, along transects on the Finger Reef slope, tufts of $M$. bouillonii growing independently of shrimp were observed interspersed with Halimeda sp. on the underside of overhanging reef structures. The lack of $M$. bouillonii-A. frontalis colonies growing in this fashion might hint at the process by which these colonies are initiated. Shrimp may be collecting free filaments from the underside of overhangs and then moving the filaments to interstitial spaces to begin weaving, resulting in colonies tending to be found in the cryptic benthic spaces known to be favored by snapping shrimp (Johnson, Everest and Young 1947). However, more studies are needed to understand the origins of $M$. bouillonii-A. frontalis colonies.

When observations, such as the anecdotal data compiled in the supplemental knowledge aggregation questionnaire (see Supplemental Methods and Results), are combined with the gathered field data, a picture of $M$. bouiilonii-A. frontalis colony growth habits emerges that is strikingly similar to that described in historical studies. Both Cowles (1913) and Fishelson (1966) described this species pair as being found under coral rubble and stones, while Hoffmann and Demoulin (1991) assert that M. bouillonii habitually grows in the gaps between coral structures and in cavities in the reef, highlighting the cryptic nature of $M$. bouillonii-A. frontalis colony growth, and the tendency of these colonies to limit exposure by occupying interstices. Others have described shrimp-associated $M$. bouillonii growing as mats (Engene, Coates and Gerwick 2010; Engene et al. 2012) and tubes (Tidgewell et al 2010) that were attached to debris such as rocks and wood, or growing between coral structures (Matthew, Schupp and Luesch 2008; Engene, Coates and Gerwick 2010).

The most notable difference between the sites surveyed in the present study and that which was studied in Aka Jima by Yamashiro et al. (2014) is that no colonies were found to be associated with gorgonians or other soft corals in Guam or Saipan, whereas colonies in Aka Jima were reported to display an overgrowth morphology exclusively on the surfaces of gorgonians, despite scleractinian coral substrates being available (Yamashiro, Isomura and Sakai
2014). All colonies of M. bouillonii and A. frontalis encountered thus far within the Mariana Islands displayed variable, substrate-dependent growth forms that favor occupation of interstitial spaces on coral reefs. This suggests that $M$. bouillonii-A. frontalis colonies may not exhibit a similar propensity to overgrow habitats dominated by hard coral as to that reported for habitats dominated by octocoral (Yamashiro, Isomura and Sakai 2014). While neither the current study nor the Yamashiro et al. (2014) work directly measured growth dynamics, the static growth morphologies documented between these studies contrast sharply.

Although unusual, evidence of gorgonian tissue damage, and apparent boring and anchoring of cyanobacterial filaments into gorgonian tissue at Aka Jima strongly suggest that the shrimp could sustain $M$. bouillonii-A. frontalis colonies long enough to overgrow A. reticulata. What are not clear are the factors that may have influenced relatively cryptic, interstitial colonies to transition into conspicuous colonies inhabiting sea fans in Aka Jima. One hypothetical explanation could be that colonies at Aka Jima were initiated by a mechanism alternative to A. frontalis weaving $M$. bouillonii directly on the sea fans, such as a typhoon or other dramatic hydrographic activity that could dislodge colonies from the benthos. Such colonies could then have become entangled in the finely branched arms of gorgonians, and subsequently sustained by a shrimp which survived the transplant. Consistent with this hypothesis, Aka Jima has been described in the literature and field station records as having a high frequency of typhoons and other strong oceanographic conditions (Iwao 2018). Dislodgement of benthic cyanobacteria from their growth substrate by wave action has been previously reported in the scientific literature (Becerro, Bonito and Paul 2006). Yamashiro et al. (2014) report that other algal species were also tangled among the gorgonians, and gorgonians are well known to position their growth axis perpendicular to water flow in order to facilitate filtration of food particles from the water column (Leversee 1976). Thus, it is conceivable that dislodged benthic cyanobacterial colonies could become entangled in the finely branched structure of a gorgonian coral.

Furthermore, the observed patterns in pigmentation change, considered alongside the nutrient analyses, help to better characterize the commensal interactions 
occurring between $M$. bouillonii and A. frontalis, and provide further evidence for the notions presented by Yamashiro et al. (2014) in that with A. frontalis, the chemically defended $M$. bouillonii could persist on sea fans in nutrient-depleted waters. M. bouillonii is potentially gaining, through its association with $A$. frontalis, the benefit of greater access to nutrients via shrimp excrement. By the end of the experiment, the pigmentation of the non-shrimp associated cyanobacteria being grown with a shrimp matched that of the shrimp associated cyanobacteria being grown with a shrimp, suggesting that non-shrimp associated cyanobacteria with exposure to shrimp had access to more nutrients, and so were able to further develop their nitrogen-rich pigmentation (e.g., chlorophyll a and phycoerythrin). In contrast, shrimp associated cyanobacteria that were denied access to shrimp were negatively impacted by their new nutrient-poor environment and required approximately two weeks to acclimate to the new conditions. This interpretation is further supported by the three replicates of shrimp associated cyanobacteria growing with shrimp whose shrimp-driven nutrient influence was removed during the course of the experiment via death or escape; in all three of these cases, cyanobacterial pigmentation deteriorated as the nutrient-supplying shrimp was no longer actively excreting among the filaments. Further support can be found in the results of the nutrient analyses, which found statistically significantly higher levels of phosphate, nitrate, nitrite, and ammonia within the tubes of $M$. bouillonii-A. frontalis colonies, as compared to ambient seawater. This suggests that enclosed tubes and chambers of $M$. bouillonii limit water exchange, allowing for shrimp excrements to accumulate and create a beneficial nutrient-enriched environment within their confines.

A. frontalis has been described as an obligate tube dweller that benefits from its association with $M$. bouillonii by deriving chemically defended shelter (Fishelson 1966; Banner and Banner 1982; CruzRivera and Paul 2002, 2006). This benefit is exemplified during the collection of $A$. frontalis, as even very short periods of time during which shrimp are not completely enshrouded in cyanobacterial filaments can result in swift predation by invertivorous fishes (Leber, Biggs and Gerwick, unpublished observations). Another reported benefit is use of $M$. bouillonii by A. frontalis as a food source; Fishelson (1966) reported observing A. frontalis eating filaments of $M$. bouillonii and detecting cyanobacterial cells in shrimp excrement. The changes in wet weight recorded in the culturing experiment, namely the statistically significant effect of shrimp presence on changes in wet weight, provide further support that one benefit shrimp are gleaning from their cyanobacterial home is a source of food. Cultures that included shrimp saw notable decreases in wet weight, resulting from shrimp feeding upon the filaments. This brings into focus a seemingly paradoxical situation where $M$. bouillonii appears to benefit from the nutrient-enrichment provided by $A$. frontalis that allows for the development of its rich pigmentation, while also being limited to a degree in its ability to increase in biomass as $A$. frontalis benefits from M. bouillonii as a food source.

While there is more to be learned about the association between M. bouillonii and A. frontalis, this report expands on the limited knowledge of the habitat ecology of this unique symbiosis through the consideration of patterns in growth morphology in the Mariana Islands. Specifically, we demonstrate that $M$. bouillonii and $A$. frontalis consistently occupy the interstitial spaces of coral structures and other hard substrates, rather than overgrowing the external surfaces of living coral colonies. Furthermore, this report gives more dimension to the commensal partnership between $M$. bouilloni and A. frontalis by providing additional evidence to explain how both organisms benefit from their intimate association with each other.

Acknowledgements We appreciatively acknowledge Drs. P. Boudreau (University of Mississippi), L. T. Tan (Nanyang Technological University, Singapore), A. C. Jones (Gordon and Betty Moore Foundation), D. H. Sherman (University of Michigan), D. J. Edwards (California State University, Chico), A. Pereira (Gilead Sciences), N. Moss (Arzeda), L. Simmons (Vectura Group), R. V. Wilson (Biogen), B. Miller (University of Utah), P. Flatt (Western Oregon University), N. Engene (Vattenmyndigheten Västerhavet), and R. C. Coates (Joint BioEnergy Institute) for their contributions to the M. bouillonii data aggregation questionnaire. We acknowledge Dr. N. Moss previously of Scripps Institution of Oceanography, UCSD and A. Townsend, D. Drake, and T. Mesa of University of Guam Marine Laboratory for assisting with in-field surveys, as well as Dr. N. Moss and Dr. T. Leão of UCSD for guidance in genomic DNA extraction and 16S rRNA sequencing and A. B. Strum of Florida Atlantic University, Harbor Branch Oceanographic Institute, for culture experiment monitoring support. We also acknowledge A. Duenas, J. Miller, J. Peralta, and J. Cummings of University of Guam Marine Laboratory for field and logistical support, and S. Becker, M. Miller, J. Ballard, and the Oceanographic Data Facility at Scripps Institution of Oceanography for nutrient analyses. 
Authors' Contributions CAL, AJR, JSB, and WHG conceived of and designed the study. All authors conducted field surveys and collections. CAL and AJR conducted the culturing experiment and water sample collection for nutrient analyses. CAL analyzed and interpreted data. All authors wrote and edited the final manuscript.

Funding We acknowledge the National Institutes of Health (NIH) under NCI CA100851 and GM107550 for partial support of this reported work. C.A.L. gratefully acknowledges support from the UCSD Regents Pre-Doctoral Fellowship, the Robert L. Cody Memorial Pre-Doctoral Fellowship, the Kaplan Trust CMBB Pre-Doctoral Fellowship, NIH Training Program in Marine Biotechnology (T32GM067550), and The Explorers Club Exploration Fund Grant.

Data availability $16 \mathrm{~S}$ rRNA sequence data associated with this project can be accessed via NCBI under the accession numbers MT826199.1, MT826200.1, MK299234.1, MK299235.1, MT826201.1, MT826202.1, MK299236.1, MK299237.1, MT826203.1， MT826204.1， MT826205.1, MT826206.1, MT826207.1, and MT826208.1. All other data pertinent to this study have been included in this manuscript or in the supplementary information.

\section{Compliance with ethical standards}

Conflict of interest The authors declare no competing interests.

Ethics approval Scientific collections and field surveys were conducted on Guam under a Guam Department of Agriculture permit (SC-15-005) issued to Biggs.

Open Access This article is licensed under a Creative Commons Attribution 4.0 International License, which permits use, sharing, adaptation, distribution and reproduction in any medium or format, as long as you give appropriate credit to the original author(s) and the source, provide a link to the Creative Commons licence, and indicate if changes were made. The images or other third party material in this article are included in the article's Creative Commons licence, unless indicated otherwise in a credit line to the material. If material is not included in the article's Creative Commons licence and your intended use is not permitted by statutory regulation or exceeds the permitted use, you will need to obtain permission directly from the copyright holder. To view a copy of this licence, visit http://creativecommons.org/licenses/by/4.0/.

\section{References}

Banner DM, Banner AH (1982) The alpheid shrimp of Australia. Rec Aust Mus Suppl 34:359-362

Becerro MA, Bonito V, Paul VJ (2006) Effects of monsoondriven wave action on coral reefs of Guam and implications for coral recruitment. Coral Reefs 25:193-199. https://doi. org/10.1007/s00338-005-0080-7
Carpenter EJ, Subramaniam A, Capone DG (2004) Biomass and primary productivity of the cyanobacterium Trichodesmium spp. in the tropical N Atlantic ocean. Deep Sea Res Part I Oceanogr Res Pap 52:173-203. https://doi. org/10.1016/j.dsr.2003.10.006

Cowles RP (1913) The habits of some tropical Crustacea. Philipp J Sci 8:119-125

Cruz-Rivera E, Paul VJ (2002) Coral reef benthic cyanobacteria as food and refuge: diversity, chemistry and complex interactions. In: Proceedings of 9th international coral reef symposium, vol 1, pp 515-520

Cruz-Rivera E, Paul VJ (2006) Feeding by coral reef mesograzers: algae or cyanobacteria? Coral Reefs 25:617-627. https://doi.org/10.1007/s00338-006-0134-5

Davie PJF, Short JW (2001) Decapod Crustacea of North East Cay, Herald Cays, Coral Sea in Herald Cays Scientific Study Report. The Royal Geographical Society of Queensland, Inc, Brisbane 79-84

Engene N, Coates RC, Gerwick WH (2010) 16S rRNA heterogeneity in the filamentous marine cyanobacterial genus Lyngbya. J Phycol 46:591-601. https://doi.org/10.1111/j. 1529-8817.2010.00840.x

Engene $\mathrm{N}$ et al (2012) Moorea producens gen. nov., sp. nov. and Moorea bouillonii comb. nov., tropical marine cyanobacteria rich in bioactive secondary metabolites. Int J Syst Evol Microbiol 62:1171-1178. https://doi.org/10.1099/ijs. 0.033761-0

Fishelson L (1966) Observations on the littoral fauna of Israel, $\mathrm{V}$. on the habitat and behaviour of Alpheus frontalis $\mathrm{H}$. Milne-Edwards (Decapoda, Alpheidae). Crusteceana 11:98-104. https://doi.org/10.1163/156854066X00496

Frias-Lopez J, Bonheyo GT, Jin Q, Fouke BW (2003) Cyanobacteria associated with coral black band disease in Caribbean and Indo-Pacific reefs. Appl Environ Microbiol 69:2409-2413. https://doi.org/10.1128/AEM.69.4.24092413.2003

Gochfeld DJ (2010) Territorial damselfishes facilitate survival of corals by providing an associational defense against predators. Mar Ecol Prog Ser 398:137-148. https://doi.org/ 10.3354/meps08302

Hoffmann L, Demoulin V (1991) Marine cyanophyceae of papua new Guinea. II. Lyngbya bouillonii Sp. Nov., a remarkable tropical reef-inhabiting blue-green alga. Belj J Bot 124:82-88

Iwao K (2018) Chapter b - Status of coral reefs around the country: Kerama Islands. In: Iguchi A and Hongo C (eds) Coral Reefs of Japan, Springer, Ny pp. 185-189

Johnson MW, Everest FA, Young RW (1947) The role of snapping shrimp (Crangon and Synalpheus) in the production of underwater noise in the sea. Biol Bull 93:122-138. https://doi.org/10.2307/1538284

Leão T et al (2017) Comparative genomics uncovers the prolific and distinctive metabolic potential of the cyanobacterial genus Moorea. Proc Natl Acad Sci 114:3198-3203. https:// doi.org/10.1073/pnas.1618556114

Leversee GJ (1976) Flow and feeding in fan-shaped colonies of the gorgonian coral, Leptogorgia. Biol Bull 151:344-356. https://doi.org/10.2307/1540667

Luesch H, Yoshida WY, Moore RE, Paul VJ, Corbett TH (2001) Total structure determination of apratoxin A, a potent novel cytotoxin from the marine cyanobacterium Lyngbya 
majuscula. J Am Chem Soc 123:5418-5423. https://doi. org/10.1021/ja010453j

Matthew S, Schupp PJ, Luesch H (2008) Apratoxin E, a cytotoxic peptolide from a Guamanian collection of the marine cyanobacterium Lyngbya bouillonii. J Nat Prod 71:1113-1116. https://doi.org/10.1021/np700717s

Milne-Edwards H (1837) Histoire Naturelle des Crustacés, Comprenant 1'Anatomie, la Physiologie et la Classification de ces Animaux. In: Librairie Encyclopédique de Roret (1834-1840). Paris, vol 3, p 638, plates $1-42$

Nagle DG, Paul VJ (1999) Production of secondary metabolites by filamentous tropical marine cyanobacteria: ecological functions of the compounds. J Phycol 35:1412-1421. https://doi.org/10.1046/j.1529-8817.1999.3561412.x

NOAA's environmental sensitivity index: Guam and the Northern Mariana Islands shapefile. (2005) National Oceanic and Atmospheric Administration (NOAA), National Ocean Service, Office of Response and Restoration, Emergency Response Division, Seattle, Washington. https://response.restoration.noaa.gov/maps-and-spatialdata/download-esi-maps-and-gis-data.html

Nomura K, Nagai S, Asakura A, Komai T (1996) A preliminary list of shallow water decapod crustacea in the Kerama group, the Ryukyu Archipelago. Bull Biogeogr Soc Japan 51:7-21

Paerl HW, Paul VJ (2012) Climate change: Links to global expansion of harmful cyanobacteria. Water Res 46:1349-1363. https://doi.org/10.1016/j.watres.2011.08. 002

Poupin J (1998) Crustacea decapoda and stromatopoda of French polynesia. Atoll Res Bull 451:1-62. https://doi.org/ 10.5479/si.00775630.451.1

Richters F (1880) Decapoda. In: Möbius K, Richters F and von Martens E (eds) Beiträge zur Meeresfauna der Insel Mauritius und der Seychellen. Gutmann'schen Buchhandlung, Berlin, pp 139-178, plates 15-18

Schorn MA et al. (2019) Comparative genomics of cyanobacterial symbionts reveals distinct, specialized metabolism in tropical Dysideidae sponges. mBio 10: 00821. doi: https:// doi.org/10.1128/mBio.00821-19

Simões N, Apel M, Jones DA (2001) Intertidal habitats and decapod faunal assemblages (Crustacea: Decapoda) of Socotra Island, Republic of Yemen. Hydrobiologia 449:81-97. https://doi.org/10.1023/A:1017541019388

Sweet M et al (2019) Compositional homogeneity in the pathobiome of a new, slow-spreading coral disease. Microbiome 7:139. https://doi.org/10.1186/s40168-0190759-6

Tan LT, Márquez BL, Gerwick WH (2002) Lyngbouilloside, a novel glycosidic macrolide from the marine cyanobacterium Lyngbya bouillonii. J Nat Prod 65:925-928. https:// doi.org/10.1021/np010526c

Tidgewell K et al (2010) Evolved diversification of a modular natural product pathway: apratoxins $\mathrm{F}$ and $\mathrm{G}$, two cytotoxic cyclic depsipeptides from a Palmyra collection of Lyngbya bouillonii. ChemBioChem 11:1458-1466. https://doi.org/ 10.1002/cbic. 201000070

Titlyanov EA, Yakovleva IM, Titlyanov TV (2007) Interaction between benthic algae (Lyngbya bouillonii, Dictyota dichotoma) and scleractinian coral Porites lutea in direct contact. J Exp Mar Bio Ecol 342:282-291. https://doi.org/ 10.1016/j.jembe.2006.11.007

Tronholm A, Engene N (2019) Moorena gen. nov., a valid name for "Moorea Engene \& al". nom. inval. (Oscillatoriaceae, Cyanobacteria). Notulae Algarum 122:1-2

Yamashiro H, Isomura N, Sakai K (2014) Bloom of cyanobacterium Moorea bouillonii on the gorgonian coral Annella reticulata in Japan. Sci Rep 4:6032. https://doi. org/10.1038/srep06032

Publisher's Note Springer Nature remains neutral with regard to jurisdictional claims in published maps and institutional affiliations. 